for Police, Probation Service, solicitors and courts; prescription of medicines; classification of patients, e.g. ICD; medical certification, eg, fitness for work, consent to treatment, death certification; provision of certificates for the Court of Protection, e.g. CP3; Responsible Medical Officer, 'RMO', duties and commitments; completion of documents under the provisions of the Mental Health Act by consultants approved under Section 12 of the Act; completion of reports for Mental Health Review Tribunals, including Second Opinion reports; provision of psychiatric evidence as professional witness in Court, including attendance at inquests; teaching generally on medical aspects of mental handicap; supervision and training of junior medical staff and senior registrars; psychiatric and medical research; provision of consultant cover for colleagues on leave or absent; participation in medical audit; psychiatric advice on service needs, development, planning and staffing for management; attendance at professional meetings and committees; and work in connection with professional organisations, e.g. The Royal College of Psychiatrists.

Meanwood Park Hospital

D. A. SPENCER

Leeds LS6 4QB

\section{Psychiatric referrals to emergency clinics}

Dear SirS

Recent publications in the Psychiatric Bulletin, Gee (1991) and Haw et al (1987) have examined the issue of psychiatric referrals to emergency clinics. The proper assessment and management of crises and avoidance of hospitalisation when appropriate is important, especially in these days of increasingly limited NHS resources.

Our hospital recently carried out a survey of patients presenting on an urgent basis to the duty psychiatrist over two months in an effort to audit the use of this avenue of referral.

In total, 131 patients were seen as urgent referrals. We found that $70(53 \%)$ of the patients seen had referred themselves v. $33(25 \%)$ who were referred by their general practitioners. The remainder of patients had been referred by other agencies (police, social work department, Alcoholics Anonymous, etc).

Interestingly but not unexpectedly, we found that GP referrals were more likely to require urgent admission when compared to self-referrals: 24 of the $33 \mathrm{GP}$ referred patients required admission $(72 \%), \mathrm{v}$. 20 of the 70 self-referred patients $(28 \%)$.

There were more self-referrals outside working hours: 46 of the 70 self-referrals $(66 \%)$, and the admission rate for patients who self-referred rose as the day progressed. Of the 24 self-referrals seen from
0900-1700 hours, four required admission (16\%). Eight of the 28 self-referrals seen from $1700-2400$ hours required admission $(28 \%)$. Six of the 18 self-referrals seen from $2400-0900$ hours required admission (33\%). Similar trends were not evident in the GP referred population.

These findings raise several interesting questions which require further investigation. Are patients good judges of their need for acute psychiatric help? Are patients more unwell at night, or does the duty psychiatrist's threshold for admission change as the day (and night) progresses? Is the level of training of the duty psychiatrist an important factor? Do patients abuse a psychiatric emergency service because it is so freely accessible? Is a 24-hour 'walkin-as-you-please' service a luxury in our current NHS?

Gartnavel Royal Hospital

GrainNe NeILSON

1055 Great Western Road

Glasgow G120XH

\section{References}

GEe, M. (1991) Self referral admissions. Psychiatric Bulletin, 15, 329-330.

Haw, C., Lancely, C. \& Vickers, S. (1987) Patients at a psychiatric walk-in clinic-who, how, why and when. Bulletin of the Royal College of Psychiatrists, 11, 329-332.

\section{Patient involvement in their psychiatric care}

DEAR SiRS

Dr Pilgrim (Psychiatric Bulletin, 1991, 15, 370) should be reassured that considerable advances have been made with regard to patient involvement in their psychiatric care, and the issues he raises are already being seriously addressed by the profession.

We wish to make the following points in connection with the issue he raises.

(a) Consent to treatment is an issue which is afforded the highest importance in psychiatry, in which it is well recognised that mental illness raises particular problems in this respect. The Mental Health Act Commission has examined this issue and a Working Group of the College has reported on this subject in relation to patients with impaired volition.

(b) Physical treatments used in psychiatry do have powerful effects, both beneficial and adverse. We believe that any debate about the risks of treatment must also include examination of the extensive evidence as to the beneficial effects, as well as the risks of untreated serious mental illness. 